\title{
80. Unsaturated Fatty Acids and Their Derivatives.
}

Part IV. The Mechanism of Forming Stearolic Acid from Dichlorstearic Acid.

By Tsutomu Maruyama and Bunsuke Suzukr.

Institute for Chemical Research, Kyoto Imperial University.

(Comm. by U. Suzuki, M.I.A., July 13, 1931.)

Of the elimination of hydrogen halide from halogen addition products of unsaturated fatty acids, 4 possible ways are conceivable, as follows :

$$
\begin{array}{cl}
-\mathrm{CH}_{2}-\mathrm{CHX}-\mathrm{CHX}-\mathrm{CH}_{2}- & -\mathrm{CH}=\mathrm{CH}-\mathrm{CH}=\mathrm{CH}- \\
" & -\mathrm{CH}_{2}-\mathrm{C} \equiv \mathrm{C}-\mathrm{CH}_{2}- \\
" & -\mathrm{CH}=\mathrm{C}=\mathrm{CH}-\mathrm{CH}_{2}- \\
" & -\mathrm{CH}_{2}-\mathrm{CH}=\mathrm{C}=\mathrm{CH}-
\end{array}
$$

Whether or not one or more of these reactions runs preferentially according to the difference of the configurations of the halogen compounds, is not known.

If we assume that halogen is eliminated to-gether with the hydrogen connected with the adjacent carbon and which is situated on the same side of the configuration, then, from each substance of the two following configurations, compounds listed in the following table will be obtained.

(I)

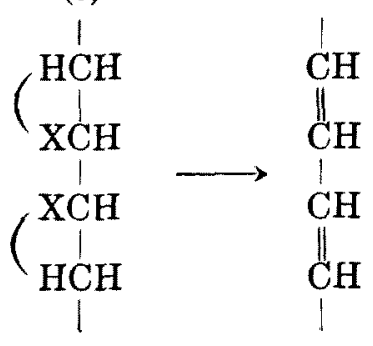

(II)

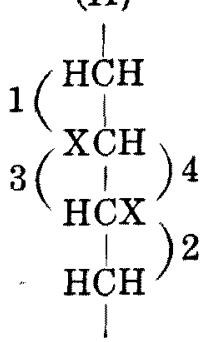

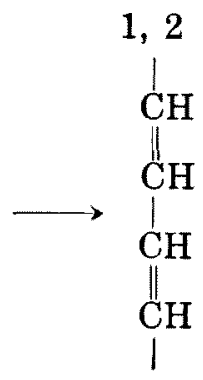

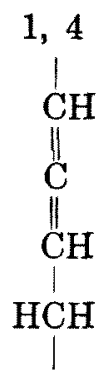

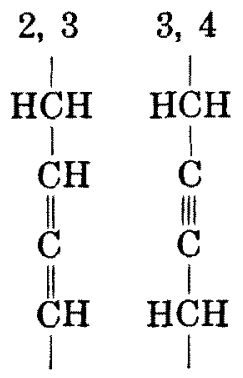

It is well known that stearolic acid (Type B) is formed when dibromo- or dichloro-stearic acid from oleic acid is treated with alcoholic potash at about $150^{\circ} \mathrm{C}$. The reaction is so common that it is used as an identification method of oleic acids. According to our assumption, the fact that stearolic acids obtained from oleo-dihalogenated stearic acid seems to show that the configuration of the acid is that of transform (II). But it is not improbable that a compound of type A may transfer secondarily to that of type B at such a high temperature as $150^{\circ} \mathrm{C}$.

As a preliminary experiment, oleo-dichlorostearic acid (10 g) (for 
this kind of experiment bromine compound should be preferably used as the oxidative power of chlorine may cause some complexities, chlorine derivative was used, in our case, however, as we had the substance in hand prepared for another experiment) was digested with alcoholic potash $\left(10 \mathrm{~g} \mathrm{KOH}\right.$ in $50 \mathrm{cc}$. of alcohol) for 12 hours at $100^{\circ} \mathrm{C}$. The methyl esters (sulfuric acid were used as the catalyst) of the resultant acids were oxidized following Armstrong and Hilditch's 's method, and oxalic acid ( $\mathrm{Ca}$ of the oxalate : $27.38 \%$, theory : $26.97 \%$ ), azelaic acid (m.p. : $106^{\circ} \mathrm{C}, \mathrm{C}: 57.08, \mathrm{H}: 8.33 \%$ (calc. C : $57.41, \mathrm{H}: 8.54$ )), suberic acid (m.p.: $140-140.5^{\circ} \mathrm{C}, \mathrm{C}: 54.92, \mathrm{H}: 8.59 \%$ (calc. C : 55.14, H : 8.10)), caprylic acid (Zn-salt; m.p.: $135^{\circ} \mathrm{C}, \mathrm{Zn}: 18.96 \%$ (calc. 18.58)), and pelargonic acid (Zn-salt; m.p.: $131^{\circ} \mathrm{C}, \mathrm{Zn}: 17.49 \%$ (calc. 17.21)) were obtained. These results suggest the presence of the acid of the constitution of $\mathrm{CH}_{3}\left(\mathrm{CH}_{2}\right)_{6} \cdot \mathrm{CH}=\mathrm{CH}-\mathrm{CH}=\mathrm{CH}\left(\mathrm{CH}_{2}\right)_{6} \mathrm{COOH}$ besides stearolic acid.

The methyl esters of another lot, prepared in the same way just described, were submitted to the distillation under reduced pressure $(4 \mathrm{~mm})$. At the temperature of $192-193^{\circ} \mathrm{C}$, a part of the esters has been distilled over quite sharply and in a good yield (50 g out of $60 \mathrm{~g}$ ).

The free acid obtained from the methyl ester has been neutralized with $\mathrm{NaOH}$ and the $\mathrm{Zn}$-salt has been formed by adding $\mathrm{ZnSO}_{4}$ to the solution. The $\mathrm{Zn}$-salt was recrystallized twice from methyl alcohol. M.p. : $85^{\circ} \mathrm{C}$. (Zn-stearolate melts at $114^{\circ} \mathrm{C}$ ) C : $69.00, \mathrm{H}: 9.82 \%$ (C : 69.26, $\mathrm{H}: 10.01$ as $\left.\left(\mathrm{C}_{18} \mathrm{H}_{31} \mathrm{O}_{2}\right) \mathrm{Zn}\right)$. The free acid formed by treating the $\mathrm{Zn}$-salt with $\mathrm{H}_{2} \mathrm{SO}_{4}$ was a liquid, $\mathrm{C}: 76.78, \mathrm{H}: 10.98 \%(\mathrm{C}: 77.09$, $\mathrm{H}$ : 11.56 as $\mathrm{C}_{18} \mathrm{H}_{32} \mathrm{O}_{2}$ ). No definite iodine value by Wij's method could be estimated as the value changed remarkably with the lapse of time. Hydrogen value was 155.9 while theory requires 157.6 as $\mathrm{CH}_{3}\left(\mathrm{CH}_{2}\right)_{6} \mathrm{CH}: \mathrm{CH} \cdot \mathrm{CH}: \mathrm{CH}\left(\mathrm{CH}_{2}\right)_{6} \mathrm{COOH}$.

The methyl ester of the purified new acid was oxidized as usual, following the method of Armstrong and Hilditch and suberic acid (m.p. : $140.5^{\circ} \mathrm{C}, \mathrm{C}: 54.65, \mathrm{H}: 8.23 \% ; \mathrm{C}: 55.14, \mathrm{H}: 8.10 \%$ as $\mathrm{C}_{18} \mathrm{H}_{1.4} \mathrm{O}_{4}$ ), caprylic acid (Zn-salt; m.p.: $135^{\circ} \mathrm{C}, \mathrm{Zn}: 18.02 \%$ ) and oxalic acid (Ca-salt; $\mathrm{Ca}: 27.38$ ) has been identified as the fission products, so that the constitution of the new acid is confirmed as $d^{3: 9,10: 11}$ octadecadienoic acid.

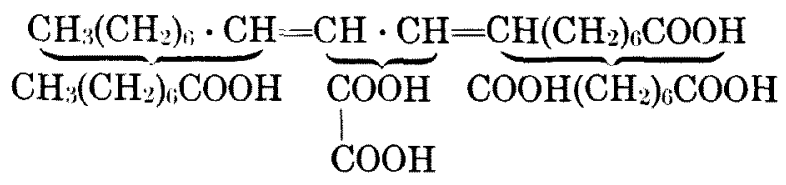

Caprylic acid Oxalic acid Suberic acid 
Arnaud and Hasenfratz ${ }^{1)}$ claim that pelargonic, caprylic, azelaic and suberic acids were obtained by the oxidation of stearolic acid with $\mathrm{KMnO}_{4}$ in alkaline medium. If the same reactions occur in Armstrong and Hilditch's process, somewhat confusing complications should result. To make sure that such complicated results are not obtained in the process, stearolic acid methyl ester was oxidized and only azelaic ( $\mathrm{Zn}$ salt ; m.p.: $\left.106^{\circ} \mathrm{C}, \mathrm{C}: 57.09, \mathrm{H}: 8.57\right)$ and pelargonic acid (Zn-salt; m.p. : $131^{\circ} \mathrm{C}, \mathrm{Zn}: 16.50 \%$ ) were obtained.

When oleo-dichloro-stearic acid are digested at $100^{\circ} \mathrm{C}$ with alcoholic potash, a mixture of stearolic acid and the new acid are formed as our preliminary experiment has shown. That this stearolic acid is formed from the new acid by the rearrangement of bonds, will be known from the following experiments.

When the new acid was treated with alcoholic potash (20\%) at the temperature of $150^{\circ} \mathrm{C}$, stearolic acid was formed almost in the theoretical yield. The stearolic acid was identified by the m.p., mixing test and analysis of the free acid as well as its $\mathrm{Zn}$-salt. The change, however, did not occur in a pure alcoholic solution. Thus stearolic acid is formed as

(At $100^{\circ} \mathrm{C}$ or
$\mathrm{CH}_{3}\left(\mathrm{CH}_{2}\right)_{6} \mathrm{CH}_{2} \mathrm{CHCl} \cdot \mathrm{CHClCH}_{2}\left(\mathrm{CH}_{2}\right)_{6} \mathrm{CO}_{2} \mathrm{H} \longrightarrow \mathrm{CH}_{3}\left(\mathrm{CH}_{2}\right)_{6} \mathrm{CH}: \mathrm{CH} \cdot \mathrm{CH}: \mathrm{CH}\left(\mathrm{CH}_{2}\right)_{6} \mathrm{CO}_{2} \mathrm{H}$
Oleo-9 : 10-dichlorostearic acid

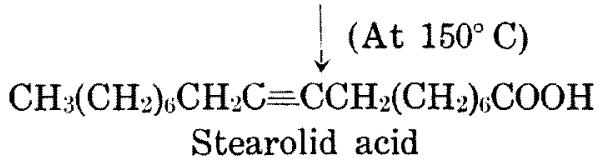

To show that these rearrangements of bonds as well as H-atoms occur in some cases generally, the experiments were carried out with sorbic acid. The positions of conjugated double bonds of sorbic acid are well established. The acid is contained in mountain berries, but to have the acid in hand in a sufficient quantity, the synthetic process of Nottbohm ${ }^{2)}$ was adopted. The process is presented briefly in the following scheme.

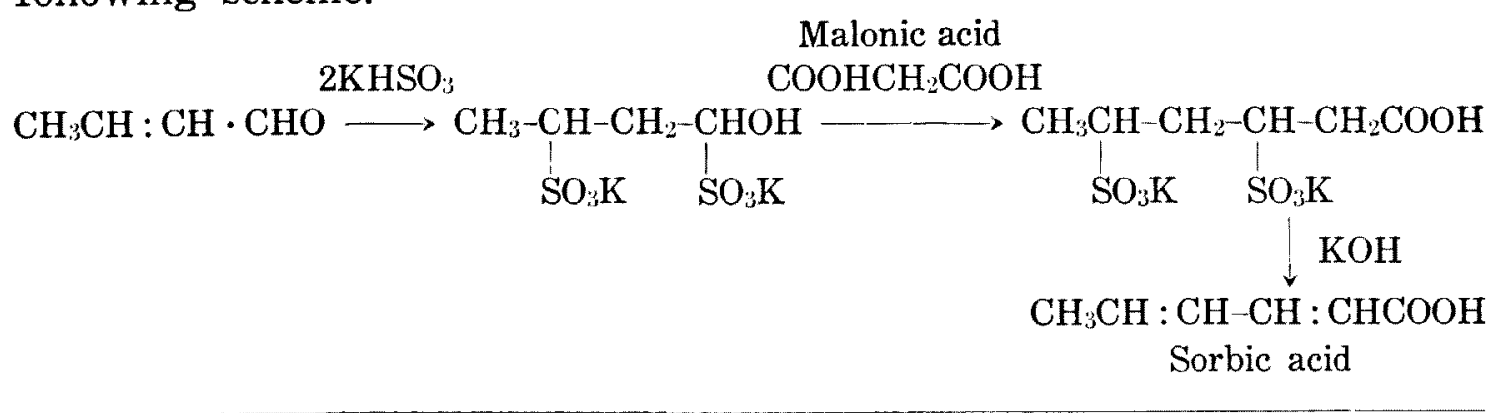

1) Compt. rend. 152, 1604.

2) Ann. 412 (1916), 49. 
Sorbic acid; m.p.: $132^{\circ} \mathrm{C}$, hydrogen value $402.25, \mathrm{C}: 63.98, \mathrm{H}$ : $7.94\left(\mathrm{C}: 64.25, \mathrm{H}: 7.20\right.$ as $\mathrm{C}_{6} \mathrm{H}_{8} \mathrm{O}_{2}$ ).

When sorbic acid was digested in a sealed tube with alcoholic potash (the mixing proportion : $0.5 \mathrm{~g}$ sorbic acid $0.7 \mathrm{~g} \mathrm{KOH} 8 \mathrm{cc}$. alcohol) at $120-150^{\circ} \mathrm{C}$, unchanged acid was recovered, at above $200^{\circ} \mathrm{C}$, an unknown resinous matter was formed but when the digestion underwent at $170^{\circ} \mathrm{C}$, a new acid (m.p.: $128^{\circ} \mathrm{C}$, hydrogen value: $408.2, \mathrm{C}: 64.67$, $\mathrm{H}: 7.58 \%$ (calc. $\mathrm{C}: 64.25, \mathrm{H}: 7.20$ )) was obtained.

The methyl ester of the new acid was oxidized by the process repeatedly mentioned and malonic acid (m.p.: $132^{\circ} \mathrm{C}, \mathrm{C}: 34.67, \mathrm{H}$ : $4.24 \%, \mathrm{C}: 34.66, \mathrm{H}: 3.88 \%$ as $\mathrm{C}_{3} \mathrm{H}_{4} \mathrm{O}_{4}$ ), propionic acid (as quinine salt, m.p.: $111.5-112^{\circ} \mathrm{C}$; as Ag-salt, $\mathrm{C}: 20.94, \mathrm{H}: 3.15, \mathrm{Ag}: 59.20 \%$ as $\mathrm{C}_{3} \mathrm{H}_{5} \mathrm{O}_{2} \mathrm{Ag}, \mathrm{C}: 19.90, \mathrm{H}: 2.81, \mathrm{Ag}: 59.63 \%$ ) and oxalic acid were identified. Oxalic acid was, probably, formed by the oxidation of malonic acid.

By the same procedure, from sorbic acid, oxalic acid and acetic acid (quinine salt; m.p. : $124^{\circ} \mathrm{C}, \mathrm{Ag}$-acetate, $\mathrm{C}: 14.70, \mathrm{H}: 1.22, \mathrm{Ag}$ : $64.77 \% ; \mathrm{C}: 14.38, \mathrm{H}: 1.81, \mathrm{Ag}: 64.64 \%$ as $\mathrm{C}_{2} \mathrm{H}_{2} \mathrm{O}_{2} \mathrm{Ag}$ ) were obtained.

From above results, the constitutions of both the acids are

Sorbic acid

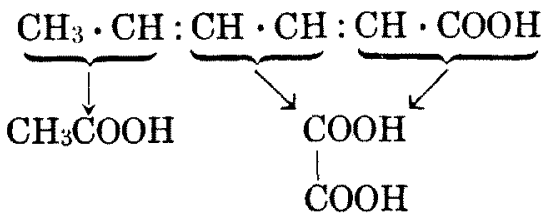

Acetic acid

Oxalic acid

\author{
The new acid \\ $\mathrm{CH}_{3} \cdot \underbrace{\mathrm{CH}_{3} \cdot \mathrm{CH}_{2} \cdot \mathrm{C}}_{\mathrm{CH}_{2} \cdot \mathrm{COOH}} \equiv \underbrace{\mathrm{C} \cdot \mathrm{CH}_{2} \cdot \mathrm{COOH}}_{\mathrm{COOH} \cdot \mathrm{CH}_{3} \cdot \mathrm{COOH}}$ \\ Propionic acid Malonic acid
}

Before accepting the above assigned constructions, two questions must be answered. It is well known that $\Delta^{\beta, r}$ carboxylic acid changes to $d^{\alpha, \beta}$ carboxylic acid by the action of bases, so that from sorbic acid, the formation of an acid of the constitution of $\mathrm{CH}_{3} \mathrm{CH}_{2} \mathrm{CH}: \mathrm{C}: \mathrm{CHCOOH}$, is suspected but in that case malonic acid should not be obtained, whereas our new acid gave the substance. The 2nd question is whether or not acetic acid is formed by the oxidation of acetone used as the solvent. This we proved as negative, estimating quantitatively that, under the conditions of the oxidation, acetone is not affected by $\mathrm{KMnO}_{4}$.

Now that the above constitutions are firmly established, it is out of the question that the new acid (3-pentin-5-carboxylic acid) was formed by the rearrangements of the bonds as well as $\mathrm{H}$-atoms from sorbic acid, as

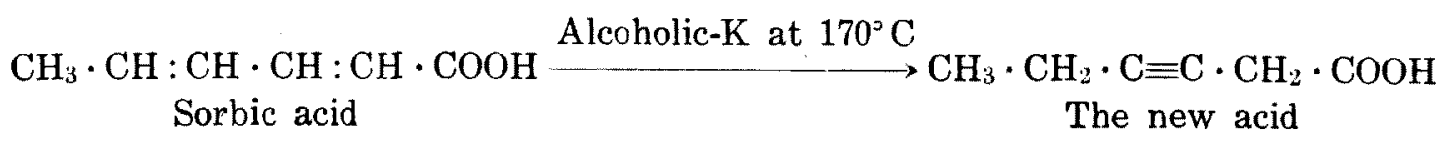

